REVIEW

\title{
Methodological issues in longitudinal studies: vestibular schwannoma growth rates in neurofibromatosis 2
}

\author{
M E Baser, V-F Mautner, D M Parry, D G R Evans
}

J Med Genet 2005;42:903-906. doi: 10.1136/jmg.2005.031302

Four longitudinal studies of vestibular schwannoma (VS) growth rates in neurofibromatosis 2 (NF2) have yielded very different results on the relationship of VS growth rates to age. The studies had different patient eligibility criteria, indices of VS growth rates, VS volumetric methods, and sample sizes. We reanalysed data from two of the longitudinal studies and used data from the population based United Kingdom NF2 Registry to determine the most likely reason for the different results and the actual relationship of VS growth rates to age. We found that the eligibility criterion in one study caused selection bias for slower growing VS. The proper interpretation of the results from the four studies is that VS growth rates in NF2 are highly variable but tend to decrease with increasing age. Clinical trials for VS in NF2 should focus on younger patients because VS growth rates tend to decrease with increasing age, and because faster growing VS are more likely to be excised with increasing age than slower growing VS.

See end of article for authors' affiliations

\section{Correspondence to:}

Correspondence to:
Dr M E Baser, 10622 Kinnard Avenue, 203, Los Angeles, CA 90024, USA; michael.baser@verizon. net

Received 24 January 2005 Revised 22 March 2005 Accepted for publication 27 March 2005
$\mathrm{N}$ F2 is a rare autosomal dominant disease characterised by vestibular schwannomas (VS), meningiomas, non-VS schwannomas, and ocular abnormalities. ${ }^{1-3}$ Bilateral VS, which occur in almost all adults with NF2, are considered to be the hallmark of the disease. The "gold standard" for imaging VSs is gadolinium enhanced magnetic resonance imaging (GEMRI).

Four longitudinal studies of VS growth rates in NF2 using GE-MRI have yielded very different results on the fundamental question of the relationship of VS growth rates to age. In the studies of Baser et $a l^{4}$ and Mautner et al, ${ }^{5} \mathrm{VS}$ growth rates decreased with increasing age. Data from these two studies can be combined because each study had the same patient eligibility criteria and volumetric methods. In combined data from the two studies, age at baseline VS measurement accounted for $19 \%$ of the variance in VS growth rates, and $75(82 \%)$ of the $93 \mathrm{VS}$ grew at least $5 \mathrm{~mm}^{3}$ /year. In the study of Slattery et al, ${ }^{6} \mathrm{VS}$ growth rates did not change significantly with increasing age. VS growth rates were not reported in terms of volumes, but in patients with longer follow-up, only four $(13 \%)$ of the 30 VS in these patients grew at least $5 \mathrm{~mm}$ in one or more linear dimensions during the study period.
In the study of Abaza et al, ${ }^{7} \mathrm{VS}$ growth rates increased with increasing age.

An understanding of the natural history of NF2 is necessary to design and interpret clinical trials properly. What can be learned from the conflicting results of these longitudinal studies? To answer this question, the reasons for the different results must be identified. The studies had different patient eligibility criteria, indices of VS growth rates, VS volumetric methods, and sample sizes. However, not all of these differences are equally likely explanations for the conflicting results.

Previously, we re-evaluated data from the study of Abaza et $a l^{7}$ and noted that the study included postoperative measurements on recurrent or residual VS, which could cause a bias toward apparently faster growing VS in older people. ${ }^{4}$ In the present study, we evaluated possible reasons for the discrepant results of the other three longitudinal studies by empirically testing the effects of the differences in study design noted above. We reanalysed data from two of the three longitudinal studies $^{45}$ (table 1) and used data from the population based United Kingdom NF2 Registry. ${ }^{89}$

\section{SOURCES OF ERROR}

\section{Patient eligibility criteria}

In the studies of Baser et $a l^{4}$ and Mautner et $a l^{5}$ (each of which found that VS growth rates decreased with increasing age), patients who had undergone excision of both VS prior to enrolment were still eligible for study if pre-operative VS volumetric measurements were available. ${ }^{45}$ In contrast, Slattery et $a l^{6}$ (who found that VS growth rates did not change with increasing age) included patients in the study only if they had at least one unoperated VS at the time. This eligibility criterion causes selection bias for slower growing VS because several conditions are fulfilled. Firstly, the excised VS grow significantly faster prior to excision than nonexcised VS. Using linear regression analysis of the combined data from Baser et $\mathrm{al}^{4}$ and Mautner et $a l,{ }^{5}$ there was a significant difference between the mean growth rates of excised and nonexcised VS when the index of VS growth rates was either $\mathrm{cm}^{3} /$ year or tumour doubling time (TDT) (table 2). Secondly, the proportion of NF2 patients with both VS excised increases with increasing age. Using Kaplan-Meier analysis of data from 479 patients in the United Kingdom

Abbreviations: GE-MRI, gadolinium enhanced magnetic resonance imaging; NF, neurofibromatosis; TDT, tumour doubling time; VS, vestibular schwannoma 
Table 1 Description of four longitudinal studies of VS growth rates in NF2

\begin{tabular}{|c|c|c|c|c|}
\hline Descriptor & Abaza ef al (1996)* & Baser et al (2002)* & Mautner ef al (2002) & Slattery ef al (2004) \\
\hline Study design & $\begin{array}{l}\text { Review of previously collected } \\
\text { MRIs }\end{array}$ & $\begin{array}{l}\text { Review of previously collected } \\
\text { MRls }\end{array}$ & $\begin{array}{l}\text { Review of previously } \\
\text { collected MRIs }\end{array}$ & Prospective \\
\hline $\begin{array}{l}\text { Eligibility criterion for VS } \\
\text { measurements }\end{array}$ & $\begin{array}{l}\text { All VS measurements, including } \\
\text { postoperative measurements on } \\
\text { recurrent or residual VS }\end{array}$ & $\begin{array}{l}\text { All pre-operative VS } \\
\text { measurements, even if both VS } \\
\text { were resected prior to } \\
\text { enrolment }\end{array}$ & $\begin{array}{l}\text { All pre-operative VS } \\
\text { measurements, even if } \\
\text { both VS were resected } \\
\text { prior to enrolment }\end{array}$ & $\begin{array}{l}\text { At least one currently } \\
\text { unoperated VS }\end{array}$ \\
\hline No. of patients & 22 & 17 & 38 & 56 \\
\hline Length of follow up & 3.7 years (mean) & 4.0 years (median) & 3.9 years (median) & $\begin{array}{l}2.4 \text { years (mean) in } 21 \text { patients } \\
\text { with long term follow up }\end{array}$ \\
\hline Volumetric method & Box model & Box model & Box model & Linear dimensions (AP, ML, GP) \\
\hline Index of VS growth rate & Volume change (in $\mathrm{cm}^{3}$ ) & & & Change in linear dimension \\
\hline $\begin{array}{l}\text { Relationship of VS growth } \\
\text { rate to increasing aqe }\end{array}$ & Increasing & Decreasing & Decreasing & No significant association \\
\hline
\end{tabular}

NF2 Registry, the cumulative proportion of NF2 patients with excised bilateral VS (that is, those who would be ineligible for the study of Slattery et $a l^{6}$ ) was about $1 \%$ by 20 years of age, $3 \%$ by 25 years, and thereafter increased more rapidly, reaching $37 \%$ by 50 years. Finally, the study of Slattery et $a l^{6}$ had only a small proportion of young NF2 patients, the group least likely to be affected by selection bias. Only about $15 \%$ of NF2 patients in the study were $<20$ years old (L. Fisher; personal communication). In sum, the eligibility criterion in the study of Slattery et $a l^{6}$ causes selection bias for slower growing VS because excised VS grow more rapidly prior to excision than non-excised VS, faster growing VS are more likely to be excised with increasing age than slower growing VS, and the study has only a small proportion of young NF2 patients.

Another type of selection bias for slower growing VS would occur if people with severe NF2, who have an early age at onset of symptoms and a high risk of mortality, also have high VS growth rates. The increased risk of mortality in NF2 patients with severe disease would cause selection bias for older NF2 patients with slow growing VS. There are too few deceased NF2 patients with available pre-mortem longitudinal VS growth measurements to directly answer this question. However, selection bias due to an increased risk of mortality in NF2 patients with severe disease probably would have a similar effect on all longitudinal studies and therefore would not explain the different results of the studies under consideration.

Table 2 Results of linear regression analyses with VS growth rates as the outcome

\begin{tabular}{lcc}
\hline $\begin{array}{l}\text { Index of VS growth rate and } \\
\text { covariates }\end{array}$ & $\begin{array}{l}\text { Regression } \\
\text { coefficient }\end{array}$ & $95 \% \mathrm{Cl}$ \\
\hline $\begin{array}{l}\mathrm{Cm}^{3} / \text { year (log10) } \\
\text { Excised VS compared to } \\
\text { non-excised VS }\end{array}$ & 0.85 & 0.11 to 1.58 \\
$\quad \begin{array}{l}\text { Age at baseline VS } \\
\text { measurement (per year) }\end{array}$ & -0.04 & -0.07 to -0.20 \\
$\begin{array}{l}\text { TDT (log10) } \\
\text { Excised VS compared to }\end{array}$ & -0.38 & -0.64 to -0.12 \\
$\begin{array}{l}\text { non-excised VS } \\
\text { Age at baseline VS } \\
\text { measurement (per year) }\end{array}$ & 0.01 & 0.00 to 0.02 \\
\hline
\end{tabular}

$\mathrm{Cl}$, confidence interval of regression coefficient; VS, vestibular schwannoma; TDT, tumor doubling time. There are two separate linear regression analyses with outcomes of $\mathrm{cm}^{3} /$ year and TDT. TDT is calculated as twice the baseline VS volume divided by the average annual VS growth rate (in $\mathrm{cm}^{3} /$ year). The analysis is based on combined data of 55 patients from Baser et $a^{4}$ and Mautner et al .

\section{Indices of growth rates for vestibular schwannoma}

Many indices can be used to estimate VS growth rates, of which TDT is a widely used index. In the studies of Baser et $\mathrm{al}^{4}$ and Mautner et al, ${ }^{5}$ TDT was calculated as twice the baseline VS volume divided by the VS growth rate, where growth rate (in $\mathrm{cm}^{3} /$ year) was calculated as a linear fit through sequential VS volumes. Baseline VS volume is factored into TDT because the growth rate of VS may depend, in part, on their size.

Slattery et $a l^{6}$ suggested that TDT might accentuate change over time because, in several studies, there was not a significant relationship between baseline VS volumes and subsequent VS growth rates. ${ }^{6}{ }^{10}{ }^{11}$ We evaluated this relationship in the combined data of Baser et $a l^{4}$ and Mautner et al. ${ }^{5}$ Logarithmic transformations were used because baseline VS volumes and VS growth rates each ranged from low to high values. There was a strong association between baseline VS volumes and subsequent VS growth rates (fig 1). It is possible that previous studies did not find this association because the data were not transformed. In addition, two of the cited studies were of unilateral sporadic VS, not NF2 associated VS. ${ }^{10}{ }^{11}$ Compared with unilateral sporadic VS, NF2 associated VS are more lobular, less vascular, and have higher proliferation indices. ${ }^{12} 13$

In some studies, VS growth rates are estimated using a model that assumes logarithmic growth, ${ }^{14}{ }^{15}$ and it has been suggested that linear models of VS growth are less appropriate with increasing length of observation because the underlying growth pattern is sigmoidal. ${ }^{14}$ However, VS growth patterns are highly variable and the probability of a sigmoidal VS growth pattern in NF2 patients is not significantly associated with the length of observation. ${ }^{5}$ VS growth curves have many patterns and a single pattern does not predominate, so a linear fit will not systematically overestimate VS growth rates in the aggregate. Some common patterns of VS growth are increasing but asymptotic growth, exponentially increasing growth, linearly increasing growth, and no growth. A linear fit overestimates growth in VS with increasing but asymptotic growth, underestimates growth in VS with exponentially increasing growth, and accurately estimates growth in VS with linearly increasing growth or no growth.

Because VS growth patterns are highly variable, it is most practical to use a curve fitting method that can be applied to all growth curves, as is the case for a linear fit. In addition to a linear fit, other indices of VS growth that do not depend on any particular pattern of growth are: $(a)$ the proportion of VS that increase by a specified change in volume within a set time; (b) Kaplan-Meier analysis of VS volumes that increase by a specified amount, in which "failure" is defined as the VS 


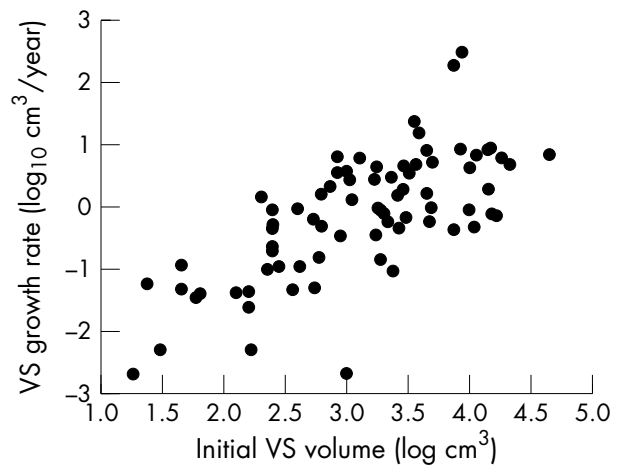

Figure 1 Association of baseline VS volume with subsequent VS growth rate. The analysis is based on 75 VS that grew at least $5 \mathrm{~mm}^{3}$ /year (combined data from Baser et $a^{4}$ and Mautner et $a^{5}$ ). $r^{2}=0.50$, $\mathrm{p}<0.001$

volume increasing by the specified amount; and (c) the proportion of VS that increase in volume more than is attributable to measurement error within a set time (or over time, as in a survival analysis). The latter method requires statistical definition of "no growth", which can be determined by repeated measures of the same VS over a short period of time in a few patients.

\section{Volumetric methods for vestibular schwannoma}

Precise MRI determined volumetrics are more accurate than box models or single dimension linear measurements, but there are several sources of variability in VS growth rates and volumetric accuracy is not necessarily the most important one. Overall variability in VS growth rates is the sum of biological variability (variability over time in the same person and variability between people) and measurement error (for example, from approximations to VS volumes using box models). In most cases, the magnitude of the biological variability of VS growth rates is much higher than the magnitude of measurement error.

To estimate the effect of volumetric precision on VS growth rates, we compared VS growth rates obtained when two different types of box models were used (we did not have information on MRI determined volumes). Box models estimate tumour volumes by setting a three dimensional box around the tumour. The three dimensions are the maximum diameters in anterior-posterior, medial-lateral, and superior-inferior dimensions. In the one component model, a single box is fitted to the entire VS. In the two component model, separate boxes are fitted to the extracanalicular and intracanalicular parts of the VS. The two component model is more accurate than the one component model when the VS has extracanalicular and intracanalicular parts. ${ }^{4}$ In fig 2, data from the study of Baser et al ${ }^{4}$ was used to compare the estimated VS growth rates of 26 VS with both extracanalicular and intracanalicular parts, using one and two component models. There was a strong association, suggesting that less precise volumetrics do not have a major overall effect on estimated VS growth rates.

\section{Sample size}

Slattery et $\mathrm{al}^{6}$ suggested that the decrease in VS growth rates with increasing age in the studies of Baser et al ${ }^{4}$ and Mautner et $a l^{5}$ could be due to small sample size, but data from the latter two studies can be combined, and as expected, the same general relationship obtains in the combined group of 55 patients as in each of the individual studies. Using linear regression analysis, VS growth rates decreased with increasing age at baseline VS measurement, whether the index of VS

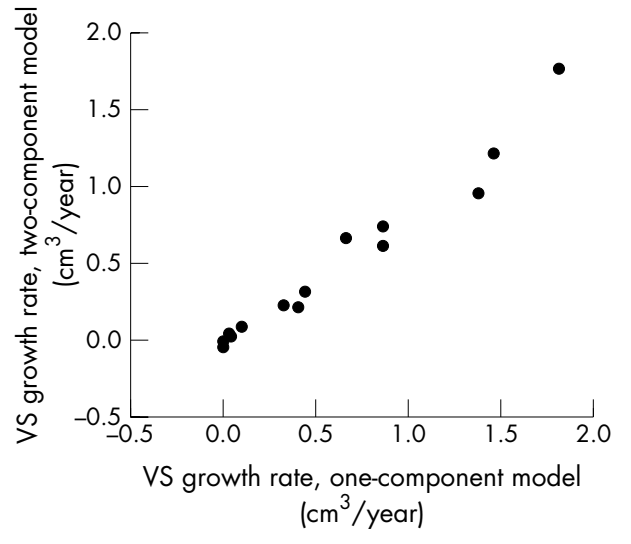

Figure 2 Comparison of VS growth rates (in $\mathrm{cm}^{3} /$ year) using one and two component box models of VS volumes (Wilcoxon signed rank test, $p=0.008$ ). The analysis is based on 26 VS with extracanalicular and intracanalicular parts (data from Baser et $a^{\mu}$ ). Two outliers are not pictured for graphical clarity.

growth rate was $\mathrm{cm}^{3} /$ year $\left(\mathrm{r}^{2}=0.23, \mathrm{p}<0.001\right)$ or TDT $\left(r^{2}=0.12, p=0.010\right)$. It is more important to note that VS growth patterns are highly variable and that none of the studies under consideration has a sufficient number of patients to characterise this variability adequately.

\section{CONCLUSION}

This study and our previous study ${ }^{4}$ illustrate that erroneous results in longitudinal studies can be caused by flawed study design or by flawed data analysis. In the study of Slattery et $a l,{ }^{6}$ the patient eligibility criterion causes selection bias for slower growing VS. The proper interpretation of the results from the four longitudinal studies ${ }^{4-7}$ is that VS growth rates in NF2 are highly variable but tend to decrease with increasing age. Clinical trials for VS in NF2 should focus on younger patients because VS growth rates tend to decrease with increasing age, and because faster growing VS are more likely to be excised with increasing age than are slower growing VS.

\section{ACKNOWLEDGEMENTS}

We thank J M Friedman and H Joe for helpful discussions.

\section{Authors' affiliations}

ME Baser, Los Angeles, CA, USA

V-F Mautner, Department of Maxillofacial Surgery, University Hospital Eppendorf, Hamburg, Germany

D M Parry, Genetic Epidemiology Branch, National Cancer Institute, Bethesda, MD, USA

D G R Evans, Academic Department of Medical Genetics, St Mary's Hospital, Manchester, UK

\section{REFERENCES}

1 Evans DGR, Huson SM, Donnai D, Neary W, Blair V, Newton V, Harris R. A clinical study of type 2 neurofibromatosis. Q J Med 1992;84:603-18.

2 Parry DM, Eldridge R, Kaiser-Kupfer MI, Bouzas EA, Pikus A, Patronas N. Neurofibromatosis 2 (NF2): clinical characteristics of 63 affected individuals and clinical evidence for heterogeneity. Am J Med Genet 1994;52:450-61.

3 Mautner VF, Lindenau M, Baser ME, Hazim W, Tatagiba M, Haase W, Samii M, Wais R, Pulst SM. The neuroimaging and clinical spectrum of neurofibromatosis 2. Neurosurgery 1996;38:880-5.

4 Baser ME, Makariou EV, Parry DM. Predictors of vestibular schwannoma growth in patients with neurofibromatosis Type 2. J Neurosurg 2002;96:217-22

5 Mautner VF, Baser ME, Thakkar S, Feigen U, Friedman JM, Kluwe L. Vestibular schwannoma growth in patients with neurofibromatosis Type 2: a longitudinal study. J Neurosurg 2002;96:223-8.

6 Slattery WH III, Fisher LM, lqbal Z, Oppenheimer M. Vestibular schwannoma growth rates in neurofibromatosis type 2 natural history consortium subjects. Otol Neurotol 2004;25:811-17. 
7 Abaza MM Makariou E, Armstrong M, Lalwani AK. Growth rate characteristics of acoustic neuromas associated with neurofibromatosis type 2 . Laryngoscope 1996;106:694-9.

8 Baser ME, Friedman JM, Aeschliman D, Joe H, Wallace AJ, Ramsden RT, Evans DG. Predictors of the risk of mortality in neurofibromatosis 2. Am J Hum Genet 2002:71:715-23.

9 Baser ME, Kuramoto L, Joe H, Friedman JM, Wallace AJ, Gillespie JE, Ramsden RT, Evans DGR. Genotype-phenotype correlations for nervous system tumors in neurofibromatosis 2: a population-based study. Am J Hum Genet 2004:75:231-9.

10 Rosenberg SI, Silverstein H, Gordon MA, Flanzer JM, Willcox TO,

Silverstein J. A comparison of growth rates of acoustic neuromas: non-surgical patients vs. subtotal resection. Otolaryngol Head Neck Surg 1993;109:482-7.
11 Nutik SL, Babb MJ. Determinants of tumor size and growth in vestibular schwannomas. J Neurosurg 2001;94:922-6.

12 Sobel RA. Vestibular (acoustic) schwannomas: histologic features in neurofibromatosis 2 and in unilateral cases. J Neuropathol Exp Neurol 1993:52:106-13.

13 Antinheimo J, Haapasalo H, Seppälä $M$, Sainio M, Carpén $O$, Jääskeläinen J. Proliferative potential of sporadic and neurofibromatosis 2-associated schwannomas as studied by MIB-1 (Ki-67) and PCNA labeling. J Neuropathol Exp Neurol 1995:54:776-82.

14 Laasonen EM, Troupp $\mathrm{H}$. Volume growth rate of acoustic neurinomas. Neuroradiology 1986;28:228-33.

15 Ogawa K, Kanzaki J, Ogawa S, Yamamoto M, Ikeda S, Shiobara R. The growth rate of acoustic neuromas. Acta Otolaryngol Suppl 1991:487:157-63.

\section{Get published within days of acceptance with JMG}

We are delighted to announce that the Journal of Medical Genetics launched a "publish ahead of print" programme in March 2005. Selected papers are fast tracked and published online months before they appear in the print journal.

Papers of more significance to the international ophthalmology community are published within days of acceptance. The first published article is the raw accepted manuscript; edited and typeset versions are also published as soon as they are available.

In addition to being available on JMG Online, the publish ahead of print articles are searchable through PubMed/Medline - establishing primacy for your work. They are linked from the JMG Online home page.

The JMG's publish ahead of print programme is unique among the major clinical genetics journals - to take advantage of this service submit your papers to Journal of Medical Genetics using our online submission and review system Bench $>$ Press (http://submit-jmg.bmijournals. com). For further information contact JMG@bmigroup.com. 